Check for updates

Cite this: Food Funct., 2019, 10, 565

\section{Agaricus blazei Murrill from Brazil: an ingredient for nutraceutical and cosmeceutical applications}

\author{
Oludemi Taofiq, (iD a,b,c Francisca Rodrigues, (D) d Lillian Barros, (DD a Rosane M. Peralta, \\ Maria F. Barreiro, ${ }^{a, b}$ Isabel C. F. R. Ferreira (D) ${ }^{a}$ and M. Beatriz P. P. Oliveira (D) ${ }^{d}$
}

Received 12th December 2018, Accepted 14th January 2019

DOI: $10.1039 / \mathrm{c} 8 \mathrm{fo} 02461 \mathrm{~h}$

rsc.li/food-function

\begin{abstract}
Operations for sorting mushrooms at the industrial level usually generate large amounts of bio-residues not conforming to strict morphological criteria for commercial purposes, even though their biological content is not compromised. In this context, the present work aimed at evaluating the potential for reutilizing industrially discarded Agaricus blazei Murill (ABM). Thus, the content of essential nutrients and the chemical composition were determined, and MTT and LDH assays were used to evaluate the viability and cell death of Caco-2 and HT29 cell lines of an ethanolic extract prepared from ABM (preliminary safety tests for nutraceutical applications). The extract was incorporated into a semi-solid base cosmetic cream and cell viability effects of the extract, and of the final cream formulation, on a keratinocyte cell line ( $\mathrm{HaCaT}$ ) were studied (preliminary safety tests for cosmeceutical applications). Essential nutrients, such as proteins and carbohydrates, and a low fat content were determined for ABM. Twenty-two fatty acids were detected, with polyunsaturated fatty acids (PUFA) ( 53\%) being the most abundant fraction. The cell viabilities of Caco-2 and HT29 cells were maintained up to $100 \mu \mathrm{g} \mathrm{mL}^{-1}$. After incorporation into the base cream, a formulation with a pale yellow colour and favourable $\mathrm{pH}$ was obtained. The cell viability of $\mathrm{HaCaT}$ cells in the presence of the extract and the final cream formulation was maintained in a concentration dependent manner, which indicates the safety of this extract for cosmeceutical applications. The results suggest that $A B M$ residues can be used as an inexpensive and sustainable source of nutraceutical and cosmeceutical ingredients.
\end{abstract}

\section{Introduction}

The concept of bio-economy has emerged to overcome sustainability challenges involving the conversion of biological wastes, agricultural residues and waste streams into high value-added products that can be employed as ingredients for several bio-based industrial processes, delivering scientific interest, a safe environment, and economic growth., Agricultural bio-residues are generated at several stages of the food supply chain, namely the primary production, processing, retailing and consumption. The most significant wastes are

\footnotetext{
${ }^{a}$ Centro de Investigação de Montanha (CIMO), Instituto Politécnico de Bragança, Campus de Santa Apolónia, 5300-253 Bragança, Portugal. E-mail: iferreira@ipb.pt ${ }^{b}$ Laboratory of Separation and Reaction Engineering (LSRE), Associate Laboratory LSRE/LCM, Polytechnic Institute of Bragança, Campus de Santa Apolónia, 1134, 5301-857 Bragança, Portugal

${ }^{c}$ GIP-USAL, Unidad de Nutrición y Bromatología, Faculty of Pharmacy, University of Salamanca, Campus Miguel de Unamuno, 37007 Salamanca, Spain

${ }^{d}$ REQUIMTE/LAQV, Department of Chemical Sciences, Faculty of Pharmacy,

University of Porto, Porto, Portugal

${ }^{e}$ Department of Biochemistry, Graduate Program in Food Science,

State University of Maringá, Paraná, Brazil
}

obtained during production and processing stages due to several pre-harvest or post-harvest conditions. ${ }^{3}$

Mushrooms are globally consumed not only because of their nutritional properties but also due to their medicinal potential and, more recently, they are increasingly used as cosmeceutical ingredients because they are rich in several bioactive compounds. ${ }^{4-6}$ Agaricus blazei Murrill (ABM) is a medicinal mushroom popularly referred to as 'Cogumelo do Sol' in Brazil, 'Himematsutake' in Japan, and 'Ji Song Rong' in China; it is rich in polysaccharides, phenolic acids and ergosterol. ${ }^{7}$ In recent years, ABM extracts have become increasingly popular because of their long history as treatments for diseases, associated with their anti-cancer, immunomodulatory, anti-inflammatory, antitumor, antioxidant and antiviral properties. ${ }^{8,9}$ This species is sometimes consumed in tea and other beverages, generating a lot of waste and by-products. Most importantly, its sorting at the industrial level usually generates bioresidues not conforming strictly to morphological criteria for commercial purposes, even though their content in valuable biomolecules is not compromised. ${ }^{10}$ These residues can be an important source of high value-added bioactive compounds, which can be further utilized as ingredients for several biobased applications. ${ }^{7}$ 
Bioactive compounds are becoming increasingly used as nutricosmetic and cosmeceutical ingredients due to their important skin health promoting properties. The former involves the oral ingestion of dietary supplements, or extracts rich in bioactive molecules, reducing the impact of free radicals and producing positive skin appearance benefits. The latter corresponds to cosmetic products, either in the form of cream or lotions, containing biologically active molecules that confer a medical drug-like effect. ${ }^{4,11-13}$ These trends are being successively described as effective, even though some research scientists continue to be skeptical and see them as a marketing twist. Commercially, nutraceutical and cosmeceutical products formulated from different mushroom extracts can be already found, either alone or combined with other mushroom species, but to the best of our knowledge Agaricus blazei has not yet been exploited. Their successful use and commercialization depend on the safety, purity and efficacy of the derived products, such as different types of extracts.

The present work was carried out to evaluate the potential to reutilize industrially discarded Agaricus blazei Murill by assessing its nutraceutical and cosmeceutical potential. Ethanolic extracts, obtained by Soxhlet extraction, were evaluated regarding their effects on cell viability and death in Caco2 and HT29 cell lines (MTT and LDH assays; preliminary safety tests for nutraceutical applications). To evaluate its dermatological potential, the extract was incorporated into a semi-solid base formulation that, together with the ethanolic extract itself, was studied for its effects on the cell viability of a keratinocyte cell line (preliminary safety tests for cosmeceutical applications).

\section{Material and methods}

\subsection{Mushroom bio-residues}

The fruiting bodies (basidiocarps) of Agaricus blazei Murrill $(\mathrm{ABM})$ were donated by a local producer in Maringá, Paraná, Brazil $\left(23^{\circ} 24^{\prime} \mathrm{S} 51^{\circ} 55^{\prime} \mathrm{W}\right)$. Those ABM fruiting bodies that were considered off-market and grouped as an agro-industrial residue were used in the present work. ${ }^{10}$ The samples were oven dried, milled to obtain a fine powder ( $\sim 40 \mathrm{mesh})$ and mixed to obtain a homogeneous sample. For all the performed tests, three samples were analysed, and all the assays were carried out in triplicate. The results are expressed as the mean values \pm standard deviation $(\mathrm{SD})$.

\subsection{Analysis of the nutritional and chemical composition of ABM bio-residues}

Proximate composition. Proteins, fat, carbohydrates and ash were determined using standard AOAC procedures. ${ }^{14}$ The sample's crude protein content $(\mathrm{N} \times 4.38)$ was estimated by the Kjeldahl method; the crude fat was determined by Soxhlet extraction using a known weight of the sample and petroleum ether as the solvent; the ash content was determined by incineration at $600 \pm 15{ }^{\circ} \mathrm{C}$. Total carbohydrates were calculated by difference and the energy content was estimated using the fol- lowing equation: Energy $(\mathrm{kcal})=4(\mathrm{~g}$ protein $)+4$ (g carbohydrate) +9 ( $\mathrm{g}$ fat $)$.

Free sugars composition. Free sugars were identified and quantified using high performance liquid chromatography coupled to refractive index detection (HPLC-RI). ${ }^{15}$ Quantification was based on calibration curves obtained from the commercial standards (D(-)-fructose, D(-)-mannitol, $\mathrm{D}(+)$-raffinose pentahydrate and $\mathrm{D}(+)$-trehalose (Sigma-Aldrich, St. Louis, MO, USA) using the internal standard (IS, raffinose) methodology. The results were recorded and processed using Clarity 2.4 software (DataApex, Prague, Czech Republic), and sugar contents were expressed in g per $100 \mathrm{~g}$ dry weight (dw).

Fatty acids composition. Samples (1.5 g) were extracted using a Soxhlet apparatus with petroleum ether as solvent. The samples undergo transesterification according to a procedure previously reported by the authors. ${ }^{15}$ Fatty acid identification was made by a comparison with relative retention times of standards (standard 47885-U, Sigma-Aldrich). The results were recorded and processed using CSW 1.7 software (DataApex 1.7, Prague, Czech Republic), and expressed in relative percentage (\%).

Tocopherol composition. Tocopherols were determined by HPLC with fluorescence detection (FP-2020; Jasco, Easton, MD, USA), using excitation at $290 \mathrm{~nm}$ and emission at $330 \mathrm{~nm} .{ }^{15}$ Quantification was done based on calibration curves obtained from commercial standards $(\alpha-, \beta-, \gamma-$, and $\delta$-tocopherols; Matreya, Pleasant Gap, PA, USA) using the IS (tocol; Matreya) methodology. The results were recorded and processed using Clarity 2.4 software (DataApex, Prague, Czech Republic) and expressed in mg per $100 \mathrm{~g} \mathrm{dw}$.

Organic acid composition. Samples (1.5 g) were extracted according to a procedure described by the authors. ${ }^{16}$ Analysis was performed using a Shimadzu 20A series UFLC (Shimadzu Corporation) coupled to a diode array detector (DAD). Quantification was made using calibration curves, obtained at $215 \mathrm{~nm}$, from commercial standards (citric, malic, oxalic, shikinic, succinic, fumaric and quinic acids; Sigma-Aldrich). The results were recorded and processed using LabSolutions Multi LC-DAD software (Shimadzu Corporation, Kyoto, Japan) and expressed in $\mathrm{g}$ per $100 \mathrm{~g} \mathrm{dw}$.

\subsection{Preparation of the AMB ethanolic extract}

The powdered samples $(3.0 \mathrm{~g})$ were extracted with $100 \mathrm{~mL}$ of ethanol under reflux in a Soxhlet apparatus. The obtained extract solutions were filtered (Whatman paper no. 4) and the solvent was evaporated under reduced pressure. The extraction yield was expressed as percentage $(\%, w / w)$ relative to the weight of the used dry sample.

\subsection{Incorporation of the ABM ethanolic extract into a semi- solid cosmetic base cream}

A cosmetic semi-solid formulation purchased from Fagron Iberica S.A.U. (Barcelona, Spain) was used in the present work. The formulation was supplemented separately with the extract at a percentage of $2.5 \%$, which corresponds to $25 \mathrm{mg}$ per gram of base cream, as previously described by the authors. ${ }^{17}$ The formulation was mixed properly to ensure sample homogenis- 
ation and then stored in tightly closed vials at $4{ }^{\circ} \mathrm{C}$. The colour and $\mathrm{pH}$ parameters were measured according to a procedure previously reported by the authors. ${ }^{18}$ Namely, the cosmeceutical formulation colour was determined using a colorimeter (model CR-400; Konica Minolta Sensing Inc., Tokyo, Japan) by sampling at three different points, and the average was considered for the true colour value. Colour space values were recorded using the data software "Spectra Magic Nx" (version CM-S100W 2.03.0006). The $\mathrm{pH}$ determination was performed, in triplicate, directly in the cream using a HI $99161 \mathrm{pH}$ meter (Hanna Instruments, Woonsocket, Rhode Island, USA).

\subsection{Preliminary safety tests for nutraceutical and cosmeceutical applications}

Cell lines and culture conditions. The human immortalized non-tumorigenic keratinocyte cell line HaCaT (Ethnicity, Caucasian; age, 62 years; gender, male; tissue, skin) was supplied by CLS Cell Lines Service, Germany. Caco-2 cells were obtained from the American Type Culture Collection (ATCC, USA) and the HT29-MTX cell line was kindly provided by Dr T. Lesuffleur (INSERM U178, Villejuif, France). Each cell line was grown separately in tissue culture flasks (Orange Scientific, Belgium). Cell lines were grown in DMEM (Carlsbad, CA) fortified with L-glutamine, 10\% inactivated fetal calf serum (FBS), an antibiotic-antimitotic mixture (final concentration of 100 $\mathrm{U} \mathrm{mL}^{-1}$ penicillin and $100 \mathrm{U} \mathrm{mL}^{-1}$ streptomycin) maintained in a $5 \% \mathrm{CO}_{2}$ incubator (Cell Culture ${ }^{\circledR} \mathrm{CO}_{2}$ Incubator, ESCO GB Ltd, UK). At 90-95\% confluence, cells were trypsinized and plated in microtiter dishes. The viable cells were counted using the trypan blue dye (Gibco) using a hemocytometer.

Caco-2 and HT29-MTX cell lines were used to evaluate the ethanolic extract's safety in nutraceutical ingredients, while the HaCaT cell line was used to evaluate the safety of both the ethanolic extract and the final cream formulation in cosmeceutical applications.

Two different assays were used to assess the effects on cell integrity: (1) monitoring the uptake of the vital mitochondrial dye, 3-(4,5-dimethylthiazol-2-yl)-5-(3-carboxymethoxyphenyl)-2(4-sulfophenyl)-2H-tetrazolium (MTT), by cell mitochondria and (2) determining the leakage of the cytosolic enzyme, lactate dehydrogenase ( $\mathrm{LDH})$, into the cell medium ( $\mathrm{LDH}$ assay). For the cell treatment, samples were dissolved in DMEM and subsequent dilutions were prepared from $1 \mu \mathrm{g} \mathrm{mL} \mathrm{m}^{-1}$ to $10 \mathrm{mg} \mathrm{mL}{ }^{-1}$. In both tests, triplicate wells were incubated with a fresh medium in the absence, or presence, of test samples.

MTT assay. Cell viability was assessed using the 3-(4,5-dimethylthiazol-2-yl)-5-(3-carboxymethoxyphenyl)-2-(4-sulfophenyl)$2 \mathrm{H}$-tetrazolium (MTT; purchased from Promega, Madison, WI) conversion assay. ${ }^{19}$ Cells were cultured in 96-well microtiter plates at a density of $25 \times 10^{3}$ cells per $\mathrm{mL}$ culture medium for $24 \mathrm{~h}$. Then, cells were incubated with $1 \mu \mathrm{g} \mathrm{mL} \mathrm{m}^{-1}$ to $10 \mathrm{mg} \mathrm{mL}^{-1}$ of both extracts and their corresponding formulations for $24 \mathrm{~h}$ at $37^{\circ} \mathrm{C}$. After the removal of samples from the wells, cells were washed with phosphate-buffered saline, followed by the addition of a fresh medium. The microtiter plates were then incubated under a humidified atmosphere of $5 \% \mathrm{CO}_{2}$ at $37{ }^{\circ} \mathrm{C}$ for $24 \mathrm{~h}$. To evaluate the number of viable cells, $100 \mu \mathrm{L}$ of MTT solution was added to each well and incubated for $4 \mathrm{~h}$ at $37^{\circ} \mathrm{C}$ in the dark. Then, the medium was removed, and the intracellular formazan crystals were solubilized and extracted with $100 \mu \mathrm{L}$ dimethylsulfoxide (DMSO). After 15 min under continuous stirring at room temperature, the absorbance was measured at $490 \mathrm{~nm}$ with background subtraction at $630 \mathrm{~nm}$ in a Synergy HT Microplate Reader (BioTek Instruments, Inc., Winooski, VT).

LDH assay. Briefly, cell lines were seeded in 96-well plates and cultured for $48 \mathrm{~h}$. Ethanolic extracts at different concentrations were prepared in an appropriate medium and added to the cells. After incubation $\left(37 \mathrm{C} / 5 \% \mathrm{CO}_{2}\right)$, cells were washed twice with PBS ( $\mathrm{pH}$ 7.4) and the LDH kit (Takara Bio Inc., Shiga, Japan) was used according to the manufacturer's instructions. ${ }^{19}$ To determine the maximum LDH release (high control), some cells were solubilized with a final concentration of 1\% (w/v) Triton X-100 (Boehringer Mannheim). The absorbance was measured at $490 \mathrm{~nm}$ with background subtraction at $690 \mathrm{~nm}$ using a Synergy HT Microplate Reader (BioTek Instruments, Inc., Winooski, VT). Each concentration was tested in triplicate in three independent experiments.

\section{Results and discussion}

\subsection{Nutraceutical potential and chemical composition of ABM bio-residues}

Studies on the chemical and bioactive composition of mushrooms have been reported over the years, aiming at identifying species with relevant biological properties and high nutritional value. ${ }^{6,20,21}$ The proximate composition of the studied ABM bio-residues, expressed on a dry weight ( $\mathrm{dw}$ ) basis, is presented in Table 1. Its components include carbohydrates (48 \pm $2 \mathrm{~g}$ per $100 \mathrm{~g} \mathrm{dw})$, crude protein $(31.6 \pm 0.5 \mathrm{~g}$ per $100 \mathrm{~g} \mathrm{dw})$, ash $(6.2 \pm 0.5 \mathrm{~g}$ per $100 \mathrm{~g} \mathrm{dw})$, and total fat $(0.66 \pm 0.08 \mathrm{~g}$ per $100 \mathrm{~g} \mathrm{dw}$ ). Carbohydrates were the major constituents, followed by proteins and ash; the fat content was low. The energy contribution was $325.3 \pm 0.5 \mathrm{kcal}$ per $100 \mathrm{~g}$ dw, mainly

Table 1 Nutritional and chemical composition of ABM bio-residues

\begin{tabular}{lc}
\hline Component & Mean \pm SD \\
\hline Nutritional value $(\mathbf{g}$ per $\mathbf{1 0 0} \mathbf{g})$ & \\
Lipids & $0.66 \pm 0.08$ \\
Proteins & $31.6 \pm 0.5$ \\
Ash & $6.2 \pm 0.5$ \\
Carbohydrates & $48 \pm 2$ \\
Energy $(k c a l$ per $\mathbf{1 0 0} \mathrm{g})$ & $325.3 \pm 0.5$ \\
Free sugars $(\mathbf{g}$ per $\mathbf{1 0 0} \mathbf{g})$ & $34.4 \pm 0.2$ \\
Mannitol & $5.1 \pm 0.2$ \\
Trehalose & $39.5 \pm 0.4$ \\
Total sugars & $17 \pm 0.6$ \\
Tocopherols $(\boldsymbol{\mu g}$ per $\mathbf{1 0 0} \mathbf{g})$ & \\
$\alpha$-Tocopherol & \\
Organic acids $(\mathbf{g}$ per $\mathbf{1 0 0} \mathbf{g})$ & $0.98 \pm 0.01$ \\
Oxalic acid &
\end{tabular}


attributed to the high carbohydrates content. Compared with a commercial A. blazei supplement obtained from Brazil, there was no significant difference in the nutritional profile (ash, $7.47 \pm 0.04 \mathrm{~g}$ per $100 \mathrm{~g}$ dw; proteins, $31 \pm 2 \mathrm{~g}$ per $100 \mathrm{~g}$ dw; fat, $1.82 \pm 0.03 \mathrm{~g}$ per $100 \mathrm{~g} \mathrm{dw}){ }^{22}$ Regarding free sugars, mannitol and trehalose were the only ones detected, and were found in similar amounts to the ones reported by Stojković et al. ${ }^{23}$ In what concerns organic acids, oxalic acid was the unique detected compound, even though Stojković et $a .^{23}$ reported the presence of fumaric acid in A. blazei samples obtained from another geographical origin, the Netherlands. Regarding the fatty acids profile, twenty-two molecules were identified (Table 2), with polyunsaturated fatty acids (PUFA) predominating (a high contribution of linoleic acid was identified), followed by saturated fatty acids (SFA) and monounsaturated fatty acids (MUFA). The distribution of fatty acids in the studied dried powder mushroom were similar to the ones reported by Carneiro et $a .^{22}$

Most of the literature reports refer to intact fruiting bodies of $\mathrm{ABM}$, while the present results show that discarded bio-residues are still promising sources of interesting biomolecules. To the best of the our knowledge, only Corrêa et $a l .{ }^{10}$ have

Table 2 Fatty acids (relative percentage, \%) in ABM bio-residues

\begin{tabular}{lc}
\hline Fatty acids & Amount $(\%)$ \\
\hline C6:0 & $0.225 \pm 0.006$ \\
C8:0 & $0.459 \pm 0.009$ \\
C10:0 & $0.319 \pm 0.003$ \\
C12:0 & $2.36 \pm 0.01$ \\
C14:0 & $1.36 \pm 0.02$ \\
C15:0 & $1.22 \pm 0.01$ \\
C15:1 & $0.056 \pm 0.001$ \\
C16:0 & $20.6 \pm 0.1$ \\
C16:1 & $0.170 \pm 0.005$ \\
C17:0 & $1.34 \pm 0.01$ \\
C18:0 & $5.58 \pm 0.02$ \\
C18:1n9 & $2.66 \pm 0.02$ \\
C18:2n6 $18: 3 n 6$ & $51.04 \pm 0.05$ \\
C20:0 & $1.47 \pm 0.02$ \\
C20:1 & $1.88 \pm 0.02$ \\
C20:2 & $0.046 \pm 0.002$ \\
C21:0 & $0.201 \pm 0.007$ \\
C22:0 & $0.572 \pm 0.001$ \\
C22:1 & $4.36 \pm 0.07$ \\
C23:0 & $2.1 \pm 0.1$ \\
C24:0 & $0.516 \pm 0.004$ \\
SFA & $1.52 \pm 0.04$ \\
MUFA & $\mathbf{4 2 . 2} \pm \mathbf{0 . 1}$ \\
PUFA & $\mathbf{5 . 0} \pm \mathbf{0 . 1}$ \\
& $\mathbf{5 2 . 7 1} \pm \mathbf{0 . 0 2}$
\end{tabular}

The results are presented as the mean \pm SD. Caproic acid (C6:0); caprylic acid (C8:0); capric acid (C10:0); lauric acid (C12:0); myristic acid (C14:0); pentadecanoic acid (C15:0); cis-10-pentadecenoic acid (C15:1); palmitic acid (C16:0); palmitoleic acid (C16:1); heptadecanoic acid (C17:0) stearic acid (C18:0); oleic acid (C18:1n9); linoleic acid (C18:2n6); gamma linolenic acid (C18:3n6); arachidic acid (C20:0); cis11-eicosenoic acid (C20:1); cis-11,14-eicosadienoic acid (C20:2); heneicosanoic acid (C21:0); behenic acid (C22:0); erucic acid (C22:1); tricosanoic acid (C23:0); lignoceric acid (C24:0); SFA - saturated fatty acids; MUFA - monounsaturated fatty acids; PUFA - polyunsaturated fatty acids. reported the reutilisation of $\mathrm{ABM}$ bio-residues to produce an ergosterol rich fraction with antioxidant and antimicrobial properties. Those authors went further by fortifying a commercial yoghurt with the obtained ergosterol rich extract, and the final formulation was found to present an enhanced antioxidant activity. ABM is therefore considered a complete "package" of healthy food, being a useful source of nutritional components as well as non-nutritional compounds, which can be orally ingested or used as food supplements to improve the wellbeing and function of the human body.

\subsection{Preliminary safety tests with the ABM ethanolic extract for nutraceutical ingredients}

To fully confirm the nutraceutical potential of the obtained $\mathrm{ABM}$ ethanolic extracts, the major challenge still lies in the assessment of their safety throughout the gastrointestinal tract since the intestinal epithelium is the major area for the absorption of bioactive molecules allowing them to reach systemic circulation. Hence, in vitro models were developed to mimic the intestinal epithelium and assess the safety of bioactive extracts. ${ }^{24}$ In the present work, the cell viability effect of the ethanolic extract prepared from ABM bio-residues on Caco2 and HT29-MTX cells in a concentration dependent manner was evaluated $\left(1-10000 \mu \mathrm{g} \mathrm{mL}^{-1}\right)$. Caco-2 cells are similar to enterocytes, while HT29-MTX cells are like the mucus producing goblet cells. Both cell lines have been widely used as intestinal models to evaluate the safety of novel nutraceutical ingredients. ${ }^{25}$ Concerning Caco-2 cells, at $100 \mu \mathrm{g} \mathrm{mL}{ }^{-1}$, cell viability was not influenced up to $80 \%$ (Fig. 1). Regarding HT29-MTX cells, up to $80 \%$ cell viability was maintained at $1 \mathrm{mg} \mathrm{mL}{ }^{-1}$, while the highest tested concentration $\left(10 \mathrm{mg} \mathrm{mL}^{-1}\right)$ was found to significantly inhibit the viability. However, above that concentration, cell viability was significantly reduced as shown in Fig. 2. The LDH assay has been utilised as a good marker to ascertain the cytotoxicity of bioactive ingredients. The mechanism behind it involves the measurement of lactate dehydrogenase (LDH), an enzyme found in the surroundings of compromised cell membranes. In the present work, both Caco-2 and HT29 cells were found to have no significant effect

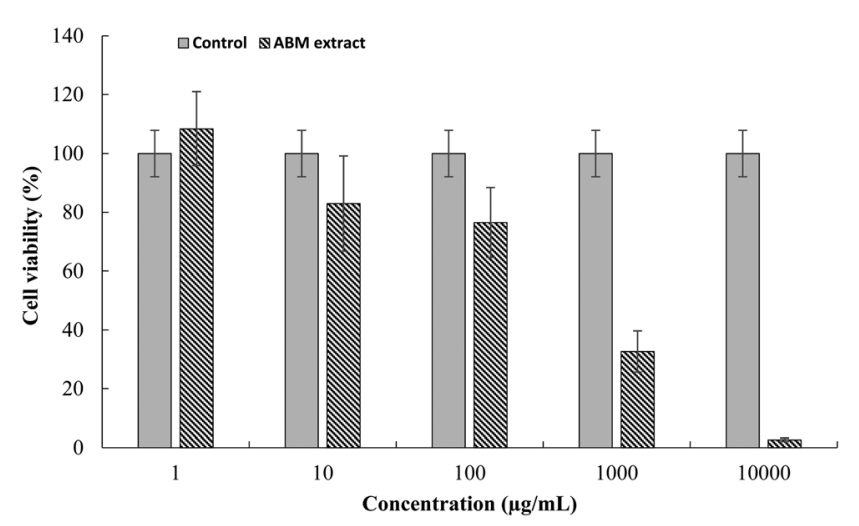

Fig. 1 Cell viability effects of the ABM ethanolic extract at different concentrations on Caco- 2 cells as measured by the MTS assay $(n=4)$. 


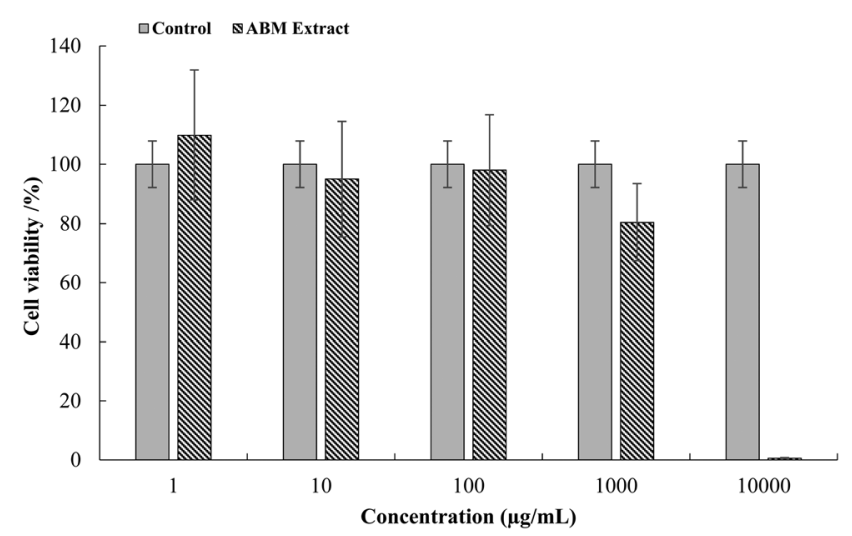

Fig. 2 Cell viability effects of the ABM ethanolic extract at different concentrations on HT29-MTX cells as measured by the MTS assay $(n=4)$.

on LDH leakage up to $100 \mu \mathrm{g} \mathrm{mL}^{-1}$ (Fig. 3). However, the LDH level was significantly detected in Caco-2 at $1 \mathrm{mg} \mathrm{mL}^{-1}$ and $10 \mathrm{mg} \mathrm{mL}{ }^{-1}$. From the obtained results, the cell viability studies in the MTT assay were consistent with what was observed in the LDH assay.

\subsection{Preliminary safety tests with the ABM ethanolic extract and the final cream formulation for cosmeceutical applications}

The global cosmetic industry has been a successful industrial sector over the years. Due to the increased awareness, coupled with the higher demand for safer and natural-based cosmetic products, innovative natural ingredients that are able to provide multifunctional benefits to the skin are of utmost importance in this industrial sector. ${ }^{4,26,27}$ In this context, mushroom-based cosmeceutical ingredients are gaining increased importance, even though they are still exploited at modest levels. Moreover, some of the bioactive properties displayed by mushroom extracts and/or their individual metabolites have led dermatologists and researchers linked to the cosmetic field to become optimistic considering the future of mushrooms and their compounds in this sector.

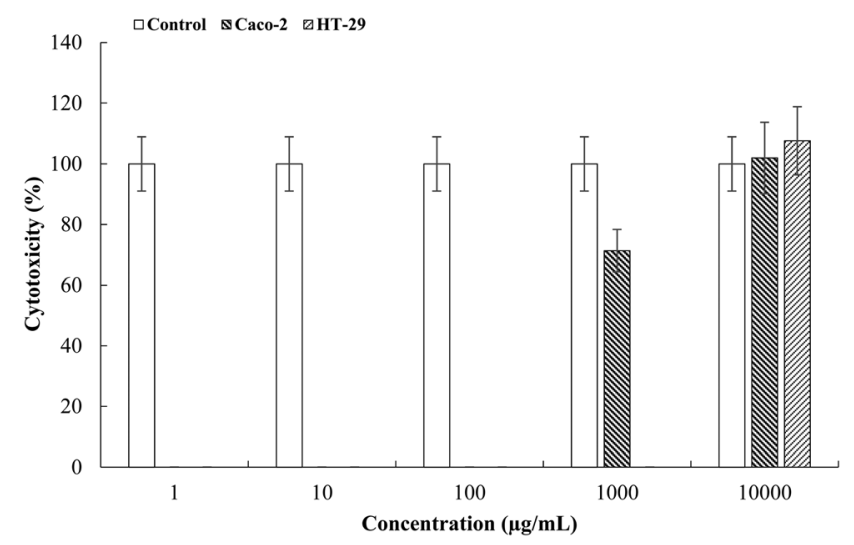

Fig. 3 Cytotoxicity effects of the ABM ethanolic extract on HT29-MTX and Caco- 2 cells at different concentrations as measured by the LDH assay.
In the present work, the incorporation of the ethanolic extract into a base cream resulted in a formulation with a lower level of lightness $\left(L^{*}\right)$ when compared with the former base cream (control). The following colour attributes using the $L^{*} a^{*} b^{*}$ scale were obtained $(74.30 \pm 0.8,9.16 \pm 0.31,19.31 \pm$ 0.48). The final $\mathrm{pH}$ of the mushroom-based formulation was $4.31 \pm 0.03$, while for the control it was $4.84 \pm 0.02$. Some studies have reported that formulations with $\mathrm{pH}$ between 3.5 and 6.0 can be considered to be favourable as most pathogenic bacteria thrive best at neutral $\mathrm{pH}$ levels and, under these conditions, the skin micro-flora and barrier homeostasis are maintained. ${ }^{28,29}$ Additionally, some of the biomolecules identified and quantified in the studied ABM bio-residues, namely tocopherols, fatty acids, organic acids and sugars, can play major roles in skin antioxidant defence, protection against photoaging, regulation of collagen synthesis, suppression of inflammatory response, normalization of epidermal lipid profiles and improvement of skin hydration and elasticity. ${ }^{30-35}$ Noteworthy is the high content of mannitol detected in the analysed ABM bioresidues (Table 1). Mannitol is largely used in cosmetics as a humectant to preserve the product from dehydration, and as a moisturising agent to prevent the dryness of the skin. In the last few years, mannitol has been considered as the ideal excipient to be used with hyaluronic acid (HA) fillers, thanks to its hydrating and antioxidant properties. ${ }^{36}$ Thus, the action of these molecules incorporated into the final formulation prepared herein can contribute to a better skin function.

Even though progress has been made in what concerns the use of natural extracts as cosmeceutical ingredients, their safety and efficacy lack appropriate reporting and dissemination. This constraint makes difficult consumers' acceptance, since they may not perceive that bioactive claims are true. In addition, the safety evaluation of ingredients for cosmeceutical applications is a critical step as some of these natural extracts contain different compounds and biomolecules that may be irritants to skin cells. In the present work, the effects of the obtained ethanolic extract on the cell viability of keratinocyte (HaCaT) cells were evaluated using MTT and LDH assays, as this cell line was previously documented as a reliable in vitro model to assess the safety of cosmeceutical ingredients. ${ }^{19}$

From the results shown in Fig. 4 for the MTT assay, the ABM ethanolic extract did not show cytotoxicity on the HaCaT cell line up to $100 \mu \mathrm{g} \mathrm{mL} \mathrm{m}^{-1}$. However, at $1 \mathrm{mg} \mathrm{mL}^{-1}$, there was a reduction in the cell viability up to $30 \%$, while a significant decrease was observed at the highest tested concentration $\left(10 \mathrm{mg} \mathrm{mL}{ }^{-1}\right)$. These results showed that higher concentrations of the extract can be deleterious for skin cells. It can also be seen that the obtained cell viability results for the extract were in accordance with the ones obtained with the corresponding formulation, namely $50 \%$ cell viability at $1 \mathrm{mg} \mathrm{mL}^{-1}$ (Fig. 5). The cytotoxicities of Agaricus blazei extracts and their individual metabolites in different cell lines have been reported,,$^{37-39}$ and in the case of Shahirah et al. ${ }^{40}$ the in vitro cytotoxicity effect of ABM using the MTT assay in a fibroblast cell line (V79-4) was determined. According to the authors, the 


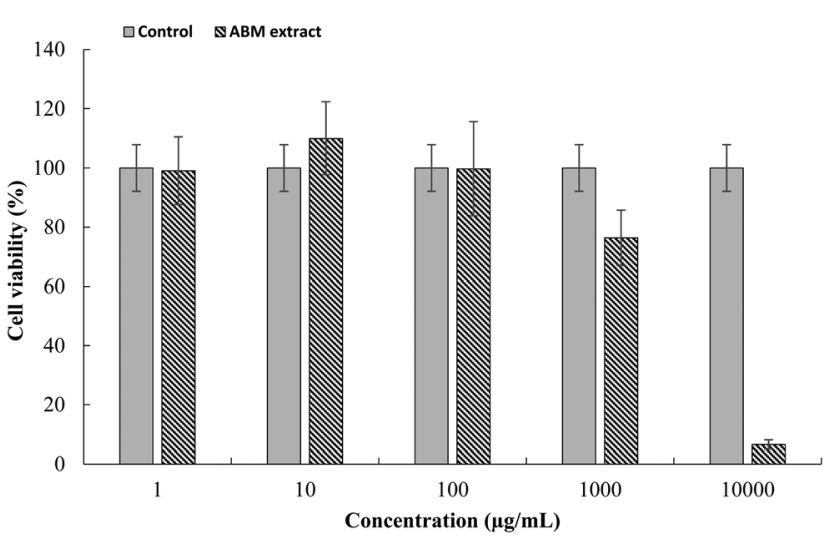

Fig. 4 Cell viability effects of the ABM ethanolic extract at different concentrations on the keratinocyte $(\mathrm{HaCaT})$ cell line as measured by the MTT assay.

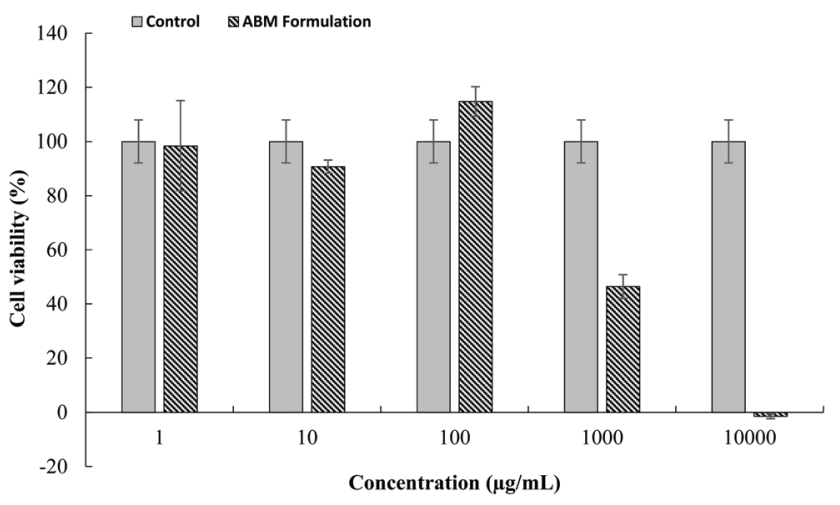

Fig. 5 Cell viability effects of the final cream formulation and the ABM ethanolic extract at different concentrations on the keratinocyte $(\mathrm{HaCaT})$ cell line as measured by the MTT assay.

extracts displayed cytotoxicity effects above $1 \mathrm{mg} \mathrm{mL} \mathrm{m}^{-1}$, which is consistent with the results achieved in the present work. To the best of the authors' knowledge, this is the first report to evaluate the safety of ABM extracts in cosmeceutical formulations, tested in a keratinocyte cell line.

\section{Conclusion}

The present study is the first report to evaluate the potential for reutilisation of A. blazei by-products, based on its nutritional and chemical composition, in nutraceutical and cosmeceutical applications. Also, the dermatological potential of an ethanolic extract was assessed through cell viability effects on a skin cell line. The presence of essential nutrients such as carbohydrates, proteins and fatty acids was demonstrated. The ethanolic extract maintained the cell viability on Caco-2 and HT29 cells at $100 \mu \mathrm{g} \mathrm{mL}{ }^{-1}$. Being rich in sugars, $\alpha$-tocopherol and organic acids makes $A$. blazei by-residues a potential ingredient for developing nutraceutical ingredients and/or functional foods, which may contribute to better nutrition and health improvement. It is also important to note that the oral administration of extracts rich in compounds with antioxidant capacity can be used to prevent the effects of cutaneous sun damage, but the efficacy of these extracts as nutricosmetics still needs to pass proper long-term clinical trials. In what concerns their cosmeceutical potential, the extract was able to maintain the cell viability in the HaCaT cell line up to $80 \%$ at $1 \mathrm{mg} \mathrm{mL}{ }^{-1}$, thus pointing to their safety for keratinocytes. The cream formulation prepared with the extract presented a lightyellow colour and a $\mathrm{pH}$ of 4.31 , which is considered suitable for skin contact purposes. The biomolecules present in ABM, namely tocopherols, fatty acids, organic acids and sugars, can also contribute to better skin appearance. To further confirm the cosmeceutical potential of ABM, skin permeation studies using Franz diffusion cells to determine the topical bioavailability of the active ingredients are needed, in addition to dermal and ocular irritability tests to ascertain safety. The results presented herein support the sustainable re-use of mushroom wastes, here demonstrated with $\mathrm{ABM}$, which are generated in significant quantities during their production chain. This is highly meaningful since global mushroom cultivation has been predicted to increase significantly in the coming years.

\section{Conflicts of interest}

There are no conflicts of interest to declare.

\section{Acknowledgements}

The authors are grateful to the Foundation for Science and Technology (FCT, Portugal) and the FEDER under Programme PT2020 for providing financial support to CIMO (UID/AGR/ 00690/2013). This work was funded by the European Agricultural Fund for Rural Development (EAFRD) through the Rural Development Program (PDR2020) within the scope of Project MicoCoating (PDR2020-101-031472), which also supported Oludemi Taofiq's research grant. Francisca Rodrigues is thankful to the project Operação NORTE-01-0145-FEDER-000011 for her postdoc research grant. Rosane Marina Peralta is a recipient of project number 307944/2015-8 from the CNPq (Conselho Nacional de Pesquisa e Desenvolvimento). This work received financial support from the European Union (FEDER funds through COMPETE) under Partnership Agreement PT2020 and National Funds (FCT, Foundation for Science and Technology) through project LAQV/UID/QUI/50006/2013 and NORTE-07-0124FEDER-000069 - Food Science. This work also received financial support through the project POCI-01-0145 FEDER-006984 (LA LSRE-LCM), funded by FEDER, through POCI-COMPETE2020 and FCT.

\section{References}

1 S. A. Heleno, M. A. Prieto, L. Barros, A. Rodrigues, M. F. Barreiro and I. C. F. R. Ferreira, Optimization of 
microwave-assisted extraction of ergosterol from Agaricus bisporus L. by-products using response surface methodology, Food Bioprod. Process., 2016, 100, 25-35.

2 L. Devaney and M. Henchion, Consensus, caveats and conditions: International learnings for bioeconomy development, J. Cleaner Prod., 2018, 174, 1400-1411.

3 C. Beausang, C. Hall and L. Toma, Food waste and losses in primary production: Qualitative insights from horticulture, Resour., Conserv. Recycl., 2017, 126, 177-185.

4 O. Taofiq, A. M. González-Paramás, A. Martins, M. F. Barreiro and I. C. F. R. Ferreira, Mushrooms extracts and compounds in cosmetics, cosmeceuticals and nutricosmetics-A review, Ind. Crops Prod., 2016, 90, 38-48.

5 S. A. Heleno, A. Martins, M. J. R. P. Queiroz and I. C. F. R. Ferreira, Bioactivity of phenolic acids: Metabolites versus parent compounds: A review, Food Chem., 2015, 173, 501-513.

6 O. Taofiq, S. A. Heleno, R. C. Calhelha, M. J. Alves, L. Barros, A. M. González-Paramás, M. F. Barreiro and I. C. F. R. Ferreira, The potential of Ganoderma lucidum extracts as bioactive ingredients in topical formulations, beyond its nutritional benefits, Food Chem. Toxicol., 2017, 108, 139-147.

7 F. Firenzuoli, L. Gori and G. Lombardo, The medicinal mushroom Agaricus blazei murrill: Review of literature and pharmaco-toxicological problems, Evidence-Based Complementary Altern. Med., 2008, 5, 3-15.

8 C. U. J. O. Lima, E. F. Gris and M. G. O. Karnikowski, Antimicrobial properties of the mushroom Agaricus blazeiintegrative review, Rev. Bras. Farmacogn., 2016, 26, 1-7.

9 F. H. Zhai, Q. Wang and J. R. Han, Nutritional components and antioxidant properties of seven kinds of cereals fermented by the basidiomycete Agaricus blazei, J. Cereal Sci., 2015, 65, 202-208.

10 R. Corrêa, L. Barros, A. Fernandes, M. Sokovic, A. Brachtc, R. M. Peralta and I. C. F. R. Ferreira, A natural food ingredient based on ergosterol: optimization of the extraction from Agaricus blazei, evaluation of bioactive properties and incorporation in yogurts, Food Funct., 2018, 1465-1474.

11 Z. D. Draelos, Nutrition and enhancing youthful-appearing skin, Clin. Dermatol., 2010, 28, 400-408.

12 M. D. Luque de Castro, Cosmetobolomics as an incipient "-omics" with high analytical involvement, TrAC, Trends Anal. Chem., 2011, 30, 1365-1371.

13 O. Taofiq, A. M. González-paramás, M. F. Barreiro and I. C. F. R. Ferreira, Hydroxycinnamic Acids and Their Derivatives: Cosmeceutical Significance, Challenges and Future Perspectives, a Review, Molecules, 2017, 22, 1-24.

14 AOAC International, Official Methods of Analysis of AOAC International, 2016, p. 44.

15 Â. Fernandes, J. C. M. Barreira, A. L. Antonio, M. B. P. P. Oliveira, A. Martins and I. C. F. R. Ferreira, Extended use of gamma irradiation in wild mushrooms conservation: Validation of $2 \mathrm{kGy}$ dose to preserve their chemical characteristics, LWT-Food Sci. Technol., 2016, 67, 99-105.

16 L. Barros, C. Pereira and I. C. F. R. Ferreira, Optimized Analysis of Organic Acids in Edible Mushrooms from
Portugal by Ultra Fast Liquid Chromatography and Photodiode Array Detection, Food Anal. Methods, 2013, 6, 309-316.

17 O. Taofiq, S. Heleno, R. Calhelha, M. Alves, L. Barros, M. Barreiro, A. González-Paramás and I. Ferreira, Development of Mushroom-Based Cosmeceutical Formulations with Anti-Inflammatory, Anti-Tyrosinase, Antioxidant, and Antibacterial Properties, Molecules, 2016, 21, 1372.

18 O. Taofiq, S. A. Heleno, R. C. Calhelha, I. P. Fernandes, M. J. Alves, L. Barros, A. M. González-Paramás, I. C. F. R. Ferreira and M. F. Barreiro, Mushroom-based cosmeceutical ingredients: Microencapsulation and in vitro release profile, Ind. Crops Prod., 2018, 124, 44-52.

19 F. Rodrigues, A. Palmeira-de-Oliveira, J. das Neves, B. Sarmento, M. H. Amaral and M. B. Oliveira, Medicago spp. extracts as promising ingredients for skin care products, Ind. Crops Prod., 2013, 49, 634-644.

20 S. A. Heleno, R. C. Ferreira, A. L. Antonio, M.-J. R. P. Queiroz, L. Barros and I. C. F. R. Ferreira, Nutritional value, bioactive compounds and antioxidant properties of three edible mushrooms from Poland, Food Biosci., 2015, 11, 48-55.

21 D. S. Stojković, L. Barros, R. C. Calhelha, J. Glamočlija, A. Ćirić, L. J. L. D. van Griensven, M. Soković and I. C. F. R. Ferreira, A detailed comparative study between chemical and bioactive properties of Ganoderma lucidum from different origins, Int. J. Food Sci. Nutr., 2014, 65, 42-47.

22 A. A. J. Carneiro, I. C. F. R. Ferreira, M. Dueñas, L. Barros, R. Da Silva, E. Gomes and C. Santos-Buelga, Chemical composition and antioxidant activity of dried powder formulations of Agaricus blazei and Lentinus edodes, Food Chem., 2013, 138, 2168-2173.

23 D. Stojković, F. S. Reis, J. Glamočlija, A. Ćirić, L. Barros, L. J. L. D. Van Griensven, I. C. F. R. Ferreira and M. Soković, Cultivated strains of Agaricus bisporus and A. brasiliensis: Chemical characterization and evaluation of antioxidant and antimicrobial properties for the final healthy product-natural preservatives in yoghurt, Food Funct., 2014, 5, 1602-1612.

24 F. Pan, L. Han, Y. Zhang, Y. Yu and J. Liu, Optimization of Caco-2 and HT29 co-culture in vitro cell models for permeability studies, Int. J. Food Sci. Nutr., 2015, 66, 680-685.

25 L. de Francisco, D. Pinto, H. Rosseto, L. Toledo, R. Santos, F. Tobaldini-Valério, T. Svidzinski, M. Bruschi, B. Sarmento, M. B. P. P. Oliveira and F. Rodrigues, Evaluation of radical scavenging activity, intestinal cell viability and antifungal activity of Brazilian propolis byproduct, Food Res. Int., 2018, 105, 537-547.

26 A. Kerdudo, P. Burger, F. Merck, A. Dingas, Y. Rolland, T. Michel and X. Fernandez, Development of a natural ingredient - Natural preservative: A case study, C. R. Chim., 2016, 19, 1077-1089.

27 F. Rodrigues, C. Pereira, F. B. Pimentel, R. C. Alves, M. Ferreira, B. Sarmento, M. H. Amaral and M. B. P. P. Oliveira, Are coffee silverskin extracts safe for topical 
use? An in vitro and in vivo approach, Ind. Crops Prod., 2015, 63, 167-174.

28 S. M. Ali and G. Yosipovitch, Skin pH: From basic science to basic skin care, Acta Derm.-Venereol., 2013, 93, 261-267.

29 J. J. Martínez-Pla, Y. Martín-Biosca, S. Sagrado, R. M. Villanueva-Camañas and M. J. Medina-Hernández, Evaluation of the $\mathrm{pH}$ effect of formulations on the skin permeability of drugs by biopartitioning micellar chromatography, J. Chromatogr. A, 2004, 1047, 255-262.

30 S. De Vaugelade, E. Nicol, S. Vujovic, S. Bourcier, S. Pirnay and S. Bouchonnet, UV-vis degradation of $\alpha$-tocopherol in a model system and in a cosmetic emulsion-Structural elucidation of photoproducts and toxicological consequences, J. Chromatogr. A, 2017, 1517, 126-133.

31 S. S. Shapiro and C. Saliou, Role of vitamins in skin care, Nutrition, 2001, 17, 839-844.

32 W. Rhimi, I. Ben Salem, R. Iatta, H. Chaabane, M. Saidi, A. Boulila and C. Cafarchia, Dittrichia viscosa L. leaves lipid extract: An unexploited source of essential fatty acids and tocopherols with antifungal and anti-inflammatory properties, Ind. Crops Prod., 2018, 113, 196-201.

33 T. Kayashima, Oxalic acid is available as a natural antioxidant in some systems, Biochim. Biophys. Acta, Gen. Subj., 2002, 1573, 1-3.

34 M. Taieb, C. Gay, S. Sebban and P. Secnazi, Hyaluronic acid plus mannitol treatment for improved skin hydration and elasticity, J. Cosmet. Dermatol., 2012, 11, 87-92.
35 K. D. Hyde, A. H. Bahkali and M. A. Moslem, Fungi-An unusual source for cosmetics, Fungal Divers., 2010, 43, 1-9.

36 P. André and F. Villain, Free radical scavenging properties of mannitol and its role as a constituent of hyaluronic acid fillers: a literature review, Int. J. Cosmet. Sci., 2017, 39, 355-360.

37 F. T. G. S. Cardozo, C. M. Camelini, M. N. S. Cordeiro, A. Mascarello, B. G. Malagoli, I. V. Larsen, M. J. Rossi, R. J. Nunes, F. C. Braga, C. R. Brandt and C. M. O. Sim̃es, Characterization and cytotoxic activity of sulfated derivatives of polysaccharides from Agaricus brasiliensis, Int. J. Biol. Macromol., 2013, 57, 265-272.

38 C. F. Kim, J. J. Jiang, K. N. Leung, K. P. Fung and C. B. S. Lau, Inhibitory effects of Agaricus blazei extracts on human myeloid leukemia cells, J. Ethnopharmacol., 2009, 122, 320-326.

39 K. A. Yamamoto, L. C. F. Galhardi, V. P. Rincão, S. A. Soares, Í. G. P. Vieira, N. M. P. S. Ricardo, C. Nozawa and R. E. C. Linhares, Antiherpetic activity of an Agaricus brasiliensis polysaccharide, its sulfated derivative and fractions, Int. J. Biol. Macromol., 2013, 52, 9-13.

40 N. N. Shahirah, M. Y. F. Zuraina, R. N. Fadilah, C. F. S. Zaila, L. Florinsiah, M. N. Norfazlina and L. L. Mun, Cytotoxicity Effect of Agaricus blazei, Grifola frondosa and Hericium erinaceus Used in Traditional Medicine, Bentham Open, 2014, 5, 27-30. 